IZA DP No. 10080

Researchers' Career Transitions over the Life Cycle

Daiji Kawaguchi

Ayako Kondo

Keiji Saito

July 2016 


\title{
Researchers' Career Transitions over the Life Cycle
}

\author{
Daiji Kawaguchi \\ University of Tokyo and IZA
}

Ayako Kondo

University of Tokyo and IZA

Keiji Saito
Change Co., Ltd

Discussion Paper No. 10080

July 2016

IZA

P.O. Box 7240

53072 Bonn

Germany

Phone: +49-228-3894-0

Fax: +49-228-3894-180

E-mail: iza@iza.org

Any opinions expressed here are those of the author(s) and not those of IZA. Research published in this series may include views on policy, but the institute itself takes no institutional policy positions. The IZA research network is committed to the IZA Guiding Principles of Research Integrity.

The Institute for the Study of Labor (IZA) in Bonn is a local and virtual international research center and a place of communication between science, politics and business. IZA is an independent nonprofit organization supported by Deutsche Post Foundation. The center is associated with the University of Bonn and offers a stimulating research environment through its international network, workshops and conferences, data service, project support, research visits and doctoral program. IZA engages in (i) original and internationally competitive research in all fields of labor economics, (ii) development of policy concepts, and (iii) dissemination of research results and concepts to the interested public.

IZA Discussion Papers often represent preliminary work and are circulated to encourage discussion. Citation of such a paper should account for its provisional character. A revised version may be available directly from the author. 
IZA Discussion Paper No. 10080

July 2016

\section{ABSTRACT}

\section{Researchers' Career Transitions over the Life Cycle ${ }^{1}$}

Based on a unique time-use survey of academic researchers in Japan, this study finds that research time decreases over the life cycle. The decrease in total hours worked and the increase in time spent on administrative tasks explain the decrease in research time. We also show that the decrease of research time partly explains why the research output of older researchers' decreases. The results suggest that proper incentives and job designs for senior researchers may increase their research output.

JEL Classification: $\quad \mathrm{J} 22, \mathrm{~J} 24, \mathrm{~J} 44$

Keywords: researchers' time use, research output, academic researchers, academic administration, education, multi-tasking

Corresponding author:

Daiji Kawaguchi

Graduate School of Economics

University of Tokyo

7-3-1 Hongo

Bunkyo-ku, Tokyo 113-0033

Japan

E-mail: kawaguchi@e.u-tokyo.ac.jp

\footnotetext{
${ }^{1}$ This research was initially conducted as a part of a project by the National Institute of Science and Technology Policy (NISTEP). Akiko Togawa provided excellent research assistance, and Kensuke Kobayashi offered helpful comments. Financial support from the JSPS KAKENHI grants (15K17072 and $16 \mathrm{H} 03630$ ) is gratefully acknowledged.
} 


\section{Introduction}

The quantity of academic researchers' publications declines as they age (Diamond 1986; Levin and Stephan 1991; Oster and Hamermesh 1998; Costas et al. 2010). Many previous studies attribute this decline in the number of publications to the deterioration of mental capacity and the attenuation of incentives for tenure and promotion, because the older a researcher is, the more likely she is a tenured full professor. More recent studies, including Kyvik and Olsen (2008), find that the negative relationship between age and output has attenuated or disappeared in recent years. Stroebe (2010) emphasizes the effect of the period before retirement on researchers' incentives and attributes senior researchers' output slowdown to their reduced incentive, due to the shortening of the planning horizon before their retirement. Researchers' career concern is apparently an important mechanism to explain the age-output relationship, and this paper attempts to measure the changes in career stages by looking at the change in researchers' time allocation as they age.

Studies that demonstrate a link between time spent on research and research output include Taylor et al. (2006) and Barham, Foltz, and Prager (2014). Taylor et al. (2006) illustrate that both teaching and service commitments have negative impacts on academic economists' research in the United States. Barham et al. (2014) show that an increase in time spent on administrative tasks related to grant applications results in a decrease in time spent on research and thus harms research output in the agricultural and life sciences.

An academic researcher's role typically involves three distinct academic activities: research, education, and administration. ${ }^{2}$ As a researcher ages, the administrative obligation, both on research teams and in academic institutions, typically increases. Link et al. (2008), for example, show that promotion to a tenured position leads to less research time and more service time at top U.S. research

2 Valorization of knowledge is often called as the third mission of universities. Researchers' activity that embodies the valorization mission of universities is arguably classified as dissemination of research outcomes to general public. These activities are classified as administration activity in our measurement. 
universities. This greater amount of time spent on service leads to less time spent on research: Using data from 13 countries, Bentley and Kyvik (2013) show that time spent on research decreases as researchers age in every academic field except for the humanities.

Gingras et al. (2008) argue that the decrease in the number of first-authored papers and the increase in the number of non-first-authored papers over the life cycle suggest that senior researchers become research team managers. Using the same reasoning, Costas and Bordons (2011) also report that junior researchers in terms of age or job rank tend to be the first authors, while senior researchers tend to be the last authors. Although Costas and Bordons's innovative approach based on the order of authorship indirectly captures senior researchers' time as lab managers, it cannot capture the time spent on administrative duties that are not directly related to research but have a significant impact on the performance of researchers' academic institutions in such areas as hiring, promotion, and budget allocation decisions, among other activities. This paper contributes to the literature by adding more explicit evidence that an average researcher in Japan, like a worker in a typical workplace, experiences a career transition from player to manager in regards to research output and time use. The resulting change in time allocation - more time on administration and less time on research - explains the declining output over a typical researcher's life cycle.

According to the Survey on Full-Time Equivalents at Universities, in Japan, researchers younger than 35 work 3,105 hours per year, while researchers ages 45-54 work 2,926 hours per year, on average. Moreover, researchers younger than 35 typically spend 471 hours on administrative tasks, whereas researchers 45-54 years old spend 601 hours, on average. The decline in total hours worked and the change in time allocation across activities explain the seemingly smaller output of older researchers. 


\section{Career Trajectory of Researchers in Japan}

Although details vary substantially across major fields, in Japan, there are two typical patterns of academic researchers' career trajectories. First, in the majority of natural science, medical science, and engineering fields, researchers who obtain a Ph.D. degree start their academic career as a postdoctoral researcher on a fixed term contract. Researchers' job ranks on these fixed term contracts are typically lecturer (jokyo), assistant (joshu), or post-doctoral fellow. Unlike the tenure-track system in the United States, researchers on fixed-term contracts are rarely directly promoted to a tenured position in the same department. Depending on the field of research, fixed-term positions can range from a few years to more than ten years. This system is more prevalent in the natural science, medical science, and engineering fields, perhaps because these fields are generally collaboration-intensive.

The second pattern is prevalent in the humanities and social sciences, as well as some natural science areas. In these fields, researchers typically start their careers as a tenured assistant professor right after completing their Ph.D. program or even before finishing the dissertation. They can expect promotion to an associate professor position in several years. This rather traditional system is more prevalent in fields where the evaluation of researchers depends on long-term performance, such as publication of books, and peer reputation counts more than publication in international peer-reviewed journals. Most fields in the humanities and social sciences fall into this category. In these fields, topranked research universities rarely hire a tenured assistant professor. Thus, a typical researcher starts her career at an education-oriented national or private university and attempts to "move up" to a research-oriented university by publishing a book and establishing a reputation in the academic field. This traditional system of "moving up" creates a problem, in that eligible young researchers are unable to work in research-oriented environments and research-oriented departments lack the stimulus of fresh-Ph.D. academics. This becomes a serious drawback in some academic fields, such as economics, that are becoming more collaboration-intensive. To overcome this drawback, some economics 
departments at top-research universities are transitioning from the traditional system to the US-style tenure-track system.

In either system - engineering departments’ post-doc style or humanities departments’ tenured faculty style - young researchers have a strong incentive to publish papers or books to find permanent jobs or "move up." Once they find a tenured job or a position at a prestigious university, the incentive to do research is arguably weakened.

Promotion from associate professor to full professor is based on performance of research and other university duties. Promotion policies vary across departments, and there is a substantial variation in the age at which a typical researcher is promoted to a full professor, even within a particular field.

Teaching load does not vary much across job ranks among tenured positions (including tenured assistant professors), while it is typically lighter for fixed-term researchers. Regarding administrative duties, full professors typically serve in more responsible positions, such as department chair or chair of a departmental committee, than associate and assistant professors. From which rank researchers can supervise Ph.D. students also varies across fields and institutions.

In natural science, medical science, and engineering fields that require substantial manpower and laboratory equipment to pursue a research project, job rank also may affect being able to administer research projects. In some fields, the boss of a laboratory must be a full professor; in the others, associate professors can also have a laboratory. Job rank, however, is not tied to the ability to administer research projects in many fields that do not require a large research team, such as the social sciences and humanities, mathematics, and theoretical physics.

Data

We use 2008 data from the Survey on Full-Time Equivalents at Universities (hereafter the Survey on FTEs 2008) conducted by the Ministry of Education, Culture, Sports, Science and Technology 
(MEXT); the details of the survey are available in Kanda and Tomizawa (2015). An original purpose of the survey was to measure full-time equivalents (FTEs) of researchers for internationally comparable statistics of Organisation of Economic Co-operation and Development (OECD) member countries. ${ }^{3}$ The Survey on FTEs 2008 asked about the amount of time spent on various activities in fiscal year 2007 (from April 2007 to March 2008), including time spent on research (completing work and reports related to research and guidance given to Ph.D. students), education (teaching classes, preparing for classes, supervising students except for Ph.D. students, and writing textbooks), and administrative tasks (attending faculty meetings and completing other administrative operational work for the university). It also asked about "research activities in the past three years (November 1, 2005 - October 31, 2008)," ${ }^{4}$ such as the number of refereed academic papers or articles accepted during the period. Using this unique dataset, we analyze the relationships among a researcher's age, time-use, and quantity of research output.

"Faculty members" in this paper refer to fulltime workers whose job title is full professor, associate professor, lecturer, or assistant professor. Although the survey also includes post-doctoral fellows and doctoral students, we limit our sample to faculty members of universities, because it is difficult to measure research productivity from the past publications of post-doctoral fellows and doctoral students. The job ranks of our sample range from assistant professor (and equivalent) to full professor, and the age range is 30 to 60 years old as of October 31, 2008. The size of our analysis sample is 2,137 .

3 OECD (2002) formulates basic definitions of FTE for international comparisons. The European Commission (EC 2009) summarizes the application of FTE to European university data.

4 One limitation of these data is that the timing of the research output and the time when the research is being conducted are not the same. Ideally, we would like to have data on the time when the research is conducted as being a few years ago and the number of outputs in subsequent years, but the order is the opposite. Yet, we believe that our results still provide good cross-sectional evidence, provided that researchers' time use or research output does not change discontinuously at a specific age. 
We mention a possible sample selection bias as a caveat. The original report of the Survey on Full-time Equivalents at Universities ${ }^{5}$ states that among 3,927 faculty members, 2,709 gave valid responses to the Survey of FTEs, resulting in a valid response rate of $69.0 \%$. The response rate was as high as $80.2 \%$ from "humanities, social science and other" fields and as low as $59.4 \%$ from "natural science" fields. The average number of research hours among researchers in "humanities, social science and other" filed was 842 , while it was 1,466 in the "natural science" field. Thus there seems to be a negative correlation between the reported average research hours and the response rate. The implication of this finding on a possible sample selection bias is not straightforward, however. The negative relationship might imply that the survey failed to capture the research hours of researchers whose research hours are long, or that those natural scientists with short research hours were less likely to respond to the survey. Although the implication is not clear, we note the differential response rates to the survey across academic fields as a caveat.

Table 1 reports the descriptive statistics. Our dependent variables are time spent on different activities and research outputs. On average, researchers spend 39.5\% of their time on research, $26.2 \%$ on education, $18.9 \%$ on administration, and the rest on public relations and outreach activities. Although the dataset includes the hours spent on various services, as shown in Table 1, many researchers report zero for such activities. Thus, we focus on time spent on research, education, and administration and others.

Research outputs are measured in three ways to capture the different aspects of research activities: first-authored refereed publications in a foreign (non-Japanese) language; all refereed publications in a foreign language, including both first-authored and non-first-authored ones, and publications in the Japanese language. The number of first-authored articles in foreign-language, refereed journals

\footnotetext{
5 Available at http://www.mext.go.jp/b_menu/toukei/chousa06/fulltime/kekka/1284881.htm in Japanese (accessed on July 17, 2016).
} 
presumably captures an original academic contribution as a main contributor, rather than as a manager of a laboratory. A researcher writes 1.6 first-authored papers during the three-year period, on average. The total number of articles in foreign-language, refereed journals presumably captures the original academic contribution as a project member, including as the leader of a laboratory. On average, researchers write 7.0 papers in the three-year period.

We pay particular attention to refereed publications in foreign languages, because most original academic findings in the hard sciences are published in international refereed journals. The number of publications in the Japanese language presumably captures activities that disseminate research outputs to wider audiences. Established researchers are often invited to write review articles in the Japanese language. On average, researchers write 5.6 articles in Japanese during the three-year period.

The academic fields covered by the survey include natural science, engineering, agricultural science, medical science, humanities and social sciences, and other miscellaneous fields, such as education, home economics, and art. In the sample, $16 \%$ of respondents are in the social sciences and humanities, ${ }^{6} 21 \%$ in natural science, $18 \%$ in engineering, $17 \%$ in agricultural science, $21 \%$ in medical sciences, and $6 \%$ in other fields. Forty percent of respondents are professors, $34 \%$ are associate professors, and $24 \%$ are assistant professors or the equivalent. ${ }^{7}$ Table 1 also summarizes other explanatory variables used in the regressions, such as job rank, age, characteristics of the institution, proportion of fixed term contracts, and other characteristics.

\section{Age Effect or Cohort Effect?}

We attempt to determine the changes of productivity and time use over the life cycle based on a

${ }^{6}$ Admittedly, social sciences and humanities are quite different from natural science, medical science, or engineering fields in many respects. Thus we conduct robustness checks that exclude researchers in social sciences and humanities and confirm that the results do not change. Specific results are available upon request.

7 Note that a full-time lecturer position in Japan is equivalent to an assistant professor position in North America. 
single cross-section of data that covers researchers of various ages. The maintained assumption to justify this approach is that the life-cycle pattern of a typical researcher's time use does not vary with the cohort to which she belongs.

Our major concern about the violation of this assumption is that the quality of researchers changes over time because of the expansion of graduate programs, particularly after the mid-1990s (School Basic Survey). Although whether the expansion of graduate programs increases or decreases the quality of researchers is not clear a priori, the expansion of graduate programs definitely changes the timing of the selection of researchers. When graduate programs have a small student capacity, admission to graduate programs is competitive, while a large student capacity makes job finding after completing a graduate program more competitive. Generally, the selection at a later stage of the research career is more reliable for selecting a high-ability researcher to an academic position, because a significant part of research ability is revealed during graduate education.

Thus, the fraction of Ph.D. students who land in academic positions among all students presumably captures students' competitiveness in finding an academic job. We calculate a selectivity measure defined as follows:

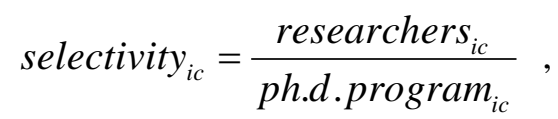

where $i$ is the index for research field, and $c$ is the birth-year cohort to control for the potential change of quality of researchers across researchers' cohorts induced by the expansion of graduate-program capacity. Likewise, the relative size of the Ph.D. program compared to the population can be used as a proxy for the selection at entry into the Ph.D. program. In the calculation of this selectivity measure, we neglect the international flow of researchers; some newly minted domestic Ph.D. holders find jobs in foreign institutions, while new Ph.D. holders from foreign graduate schools find jobs in domestic 
institutions. We note a caveat that we implicitly assume that these two flows are balanced and cancel each other out.

In the regressions, we include the log of the number of university researchers in the same field and birth-year cohort, ${ }^{8}$ taken from School Teachers Survey; the log of the number of doctoral students in the same field who entered the Ph.D. program in the year when the respondent was 25 years old, taken from School Basic Survey; and the log of the population of the respondent's birth-year cohort, taken from Vital Statistics. ${ }^{9}$ None of these control variables for the cohort effects has a statistically significant effect in any of the regressions presented in the following sections, and the estimated coefficients for other variables do not change in significant ways when these variables are excluded. Although the insignificance of these variables is not definitive evidence for the absence of a cohort effect, it at least suggests that the potentially endogenous selection is not likely to bias our estimates significantly.

\section{Aging and Academic Publications}

Figure 1 plots the average number of publications by publication type over the age of researchers. ${ }^{10}$ As a researcher ages, the number of first-authored refereed papers decreases, but the total number of refereed papers and the number of Japanese papers increase. The decrease in the number of firstauthored papers and the increase in the total number of refereed papers represent the researcher's

8 The number of university researchers is measured as of October 1, 2007, and the publicly available tabulation of the School Basic Survey shows the numbers in 5-year age categories. Accordingly, we divide our sample into the following 8 groups: born in 1943-47, 48-52, 53-57, 58-62, 63-67, 68-72, 73-77, and 78-82.

9 The School Teachers Survey is a national statistical survey conducted by MEXT. MEXT distributes the questionnaire to each school, including universities. The questionnaire asks about the composition of teaching staff by gender, age, and specialty. Vital statistics is a set of national statistics published by the Ministry of Health, Labour and Welfare. The data are tallied by birth and death registration. 10 The Survey of FTEs asks the month and year of birth. We calculate age as of October 31, 2008. 
career transition from player to manager, as already found by Gingras et al. (2008).

We need to control for differences in the age distribution across academic fields or demographic characteristics of researchers to estimate the age-publication profile based on a single cross-section of data. To control for differences in academic fields and demographic characteristics, we model a researcher's academic output as

$$
p u b_{j i}=f_{j}\left(a_{i}\right)+\beta_{j} x_{i}+u_{j i}, \ldots \text { (1) }
$$

where $p u b_{j i}$ is the number of publications in publication category $j$ of individual $i$, which depends on the age of individual $i, a_{i}$, in a potentially non-monotonic way. Specifically, we include dummies for 5 -year age categories on the right-hand side. ${ }^{11}$ The vector of control variables $x_{i}$ includes dummies for national and public universities, a dummy for research institutes without an undergraduate program, 12 category dummy variables for the major field of the department, ${ }^{12} 20$ dummy variables for the field of the respondent's own study, ${ }^{13}$ the number of institutions at which the respondent has ever worked, whether the respondent has a doctoral degree, female dummy, and foreign nationality dummy. Equation (1) is estimated as a linear regression. ${ }^{14}$

A researcher's career transition is partly represented by promotions in job ranks. To quantify career progression through promotion, we also control for dummy variables for job ranks (full professor, assistant professor, etc.). Table 2 reports the regression results of the number of publications

11 Appendix Tables A1 and A2 show that the results do not change much with different cutoffs of age categories.

12 Departments include literature, law, economics, other social sciences and humanities, science, engineering, agriculture, medical and pharmacy, other healthcarerelated majors, home economics, education, and other.

13 See Table 1 for the breakdown list.

14 Since, as shown in Table 1, many researchers report zero publications, we also estimate a Tobit model with the same set of explanatory variables. The estimated coefficients are reported in Appendix Table A3; the results are qualitatively the same. 
on age dummy variables, with and without the controls for job rank. As shown in Column (1), researchers over the age of 45 publish 0.8-0.9 fewer first-authored foreign-language papers per 3 years than researchers at ages 30-34, without controlling for rank. This reduction is statistically significant. Column (2) shows the results with the following additional control variables: dummies for job rank category (reference: professor), indicators for fixed-term contract, having adjunct affiliations with other institutes, and whether the individual researcher's field of study is the same as the major field of the department. ${ }^{15}$ Holding the job rank constant, the reduction of publications by age becomes more significant. The difference between Columns (1) and (2) implies that senior researchers who were passed over for promotion were not productive enough for the promotion. Columns (3) and (4) indicate that the total number of foreign publications increases as a researcher ages, but the positive relationship is solely due to the researcher's promotion, since the positive coefficients disappear once the rank dummy variables are controlled. Columns (5) and (6) indicate that the number of Japanese publications does not depend on age in statistically significant ways, except for the reduction of publications at ages 55 and above once the rank is controlled for. Overall, we confirm that aging reduces the number of first-authored foreign-language papers, but increases the total number of foreign-language papers, partly because of the promotion in rank, confirming the findings of Gingras et al. (2008) and Costas and Bordons (2011).

\section{Aging and Time Use}

We now turn to the analysis of time use to further shed light on an average researcher's career transition. Figure 2 shows that annual time spent on research drastically decreases during the 30s, from about 1,500 hours at age 30 to about 1,200 hours at age 40 . We observe a further reduction of the

15 We added these variables together with the job rank dummies, because they also represent the characteristics of their current job contracts. 
research time down to 1,000 hours by around age 45. In contrast, the time spent on education increases until age 40, and the time spent on administration steadily increases until the 50s. The increase in time spent on education and administration, however, is not large enough to compensate for the decrease in the time for research. Consequently, the total working hours decrease from about 3,200 in the early 30 s to about 2,300 in the 50 s.

To quantify the change of time allocation across activities, controlling for the heterogeneity of researchers, we estimate the same regression model as that for publications, replacing the dependent variable with the amount of time spent on each activity:

$$
\text { time }_{j i}=f_{j}\left(a_{i}\right)+\beta_{j} x_{i}+u_{j i},
$$

where time $_{j i}$ is the annual time use in activity $j$ of individual $i$. Like the regression model for publications, we allow time $_{j i}$ to depend on the age of individual, $a_{i}$, in a potentially non-monotonic way. The vector of control variables $x_{i}$ is the same as that for the regression for publications. Another specification includes the job rank dummy variables.

Table 3 Column (1) indicates that, on average, researchers at ages 35-39 spend about 390 hours less on research than researchers at ages 30-34. Researchers at ages 40-44 spend 490 hours less, on average, and at 45-49, they spend 670 hours less. Then the research time increases slightly in the 50s. Given that the average annual research time in the early 30s is around 1,500 hours, the hours spent on research decreases significantly: The amount of the decrease is about $26 \%$ at ages $35-39,33 \%$ at ages 40-44, and $45 \%$ at ages $45-49$, respectively, of the time spent on research at ages 30-34. Column (2) shows that the reduction of research time attenuates once the researcher's rank is controlled, implying that the reduction of research time is partly due to promotions. 
The time spent on education at ages 35-39 increases by 150 hours annually compared with those ages 30-34, as Column (3) indicates. The time spent on education additionally increases by 30 hours at ages 40-44, but goes up and down after that and sharply increases at ages 55-59. Overall, the time spent on education is particularly short at the beginning of a career and particularly long just before age 60. Column (4) indicates that the inclusion of rank dummy variables attenuates the change in time spent on education; none of the coefficients are statistically significant. Combined with the results in Column (3), the results suggest that the promotion from assistant professor to associate professor at around age 35 increases the time spent on education, and after the promotion, the time spent on education becomes stable, with an exceptional increase before retirement.

The time devoted to administrative and other tasks steadily increases as researchers age and peaks at ages 45-49, as reported in Column (5) of

Table 3. On average, researchers who are 45-49 years old spend 252 more hours than researchers who are 30-34 years old. This is a large increase, considering that, on average, researchers spend 550 hours on administrative tasks per year. The effect of aging on the amount of time spent on administrative tasks, however, attenuates by about $40 \%$ for many age ranges once the rank is controlled for, as reported in Column (6); the increase in time spent on administrative duties is strongly associated with promotion.

Overall, aging decreases the time spent on research and increases the time for administrative tasks. A 45-49 year-old researcher spends 670 hours less on research and 252 hours more on administration than a 30-34 year-old researcher. For any age range, about one-third of the reduction of research time is made up for by an increase in the time spent on administration. The time spent on education is almost stable over the life cycle, except for a light load at the beginning of the career. The change of job rank accounts for about one-third to one-half of the change in time use over the life cycle. 
The weight shift from research activity to administrative activities coincides with Link et al.'s (2008) finding that promotion to a tenured position leads to less research time and more service time at top U.S. research universities. Furthermore, the general tendency that aging reduces the time spent on research coincides with Bentley and Kyvik’s (2013) finding from 13 countries.

\section{Heterogeneous Changes in Time Use}

The aging of researchers decreases the time spent on research, on average. Is the decline because hard workers slow down or because slackers cease conducting research? Aging increases the time use for administrative tasks. Is the increase concentrated on a small number of researchers who choose a career of being an administrator, or does almost every senior researcher more or less spend their time on administrative tasks? These questions are about the heterogeneous changes of time use over the life cycle that cannot be answered by simply looking at the evolutions of average time use. To address these questions, we estimate the quantile regression models that estimate the $25^{\text {th }}, 50^{\text {th }}$, and $75^{\text {th }}$ percentiles of time-use distributions conditional on age and other demographic variables that were included in the previous regression models. Table 4a reports the estimates without controls for academic ranks, and Table $4 \mathrm{~b}$ reports those with controls for academic ranks.

The estimation results for research time use reported in Columns (1)-(3) of Table 4a show that research time significantly declines at the $75^{\text {th }}$ percentile of its distribution, while the decline at the $25^{\text {th }}$ percentile is limited. At the $75^{\text {th }}$ percentile, the research time in the late 40 s is 958 hours less than that in the early 30s, but at the $25^{\text {th }}$ percentile it is only 266 hours. This change implies that the time spent on research is very heterogeneous in the early stage of careers, but the heterogeneity decreases as the career stage progresses. The same pattern is observed with a control for academic ranks, as shown in Columns (1)-(3) of Table 4b. ${ }^{16}$

16 We should note that a researcher located at a specific percentile of the research time 
The time spent on education increases by about 200 hours until the early 40 s and becomes stable, regardless of the location in the distribution, as Columns (4) - (6) in Table 4a and 4b indicate. The homogeneous change of time for education implies that the time spent on education is equally distributed across researchers over all career stages. Columns (7) - (9) in Table 4a indicate that the time for administration increases as a researcher ages and that the increase is more significant at the upper tail of the distribution. The coefficients at the $75^{\text {th }}$ percentile of the distribution are about 1.5 times larger than those at the $25^{\text {th }}$ percentile at the maximum. Columns (7)-(9) of Table $4 \mathrm{~b}$, however, show that the difference between the $75^{\text {th }}$ percentile and the $25^{\text {th }}$ percentile substantially decreases when academic ranks are controlled. These results imply that some researchers take extra burdens as administrators in the later stage of their careers, probably because they are promoted to positions with greater responsibility.

Overall, the heterogeneity of time spent on research decreases as researchers age. Although the heterogeneity of time spent on administration increases slightly, the change is not as large as the decreases in the heterogeneity of time spent on research. Combined with the stable distribution of hours spent on education, the total hours worked becomes homogeneous as researchers age.

\section{Further evidence on career transition}

We have interpreted the relationship between researchers' age and their output and time use as being a result of career transitions. We further provide two points of evidence, somewhat anecdotal rather than comprehensive, to support the hypothesis that senior researchers gradually recede from their own research and shift weight to activities that reproduce the next generation. The first evidence is on research fund-seeking activities, and the second evidence is on mentoring activities among senior researchers.

distribution is not the researcher located at the same percentile of the other activities. 
Regarding fund-seeking activities, we provide evidence that large-size research funds, such as the Grant-in-Aid for Specially Promoted Research (Tokubetsu Suisin) by the Japan Society for the Promotion of Science (JSPS), are typically headed by senior researchers. Tokubetsu Suisin is one of the largest public research funds supporting academic research in Japan. To examine the demographic characteristics of the principal investigator (PI) of each project, we downloaded the information of all 76 projects that are active as of fiscal year 2015 that are supported by Tokubetsu Suishin from the JSPS database. The downloaded data contain the name of each researcher but do not record his/her age, so we collect the age of PIs as of December 2015 or estimate it from the year of BA completion through a web search, including personal webpages, Wikipedia, and media reports. We were able to collect or estimate the age of 69 out of 76 PIs. The distribution of the PIs' ages is reported in Figure 3. The mean and median ages of the PIs are 58.8 and 60.0, respectively, significantly older than the mean age of researchers in the analysis sample, 45.5. This is partial, admittedly not comprehensive, evidence for the claim that senior researchers are more likely to be involved in fund-acquiring activity than their younger counterparts.

Regarding Ph.D. and junior faculty advising, we take the Physics department at the University of Tokyo as an example, because it is a large department in a single field and is considered to be one of the most competitive departments in Japan. Each laboratory has a website and lists all lab members. We record the age of each PI and the number of all laboratory members, counting all the members listed on the laboratory's webpage. The correlation between the age and the size of each laboratory appears in Figure 4. The laboratory size is relatively small when the laboratory leaders are their 40s. The size of the laboratory becomes heterogeneous when PIs are in their 50s, and some PIs have many junior members. This increase in the laboratory size of some researchers may well indicate that some senior researchers actively engage in mentoring activities. The size of the laboratory shrinks when the 
PIs enter their 60s, perhaps because they are approaching the mandatory retirement age of 65 and start the shutting-down process by not taking any more incoming students.

\section{Conclusion}

This paper reports that as academic researchers age, they devote less time to research activities mainly because of the decrease in total hours worked and partly because of the increase in hours spent on administrative tasks. The decrease in total hours worked is a natural consequence of academic researchers' life-time career concerns. Young researchers work hard to accumulate academic skills and secure a permanent academic position through publishing research outputs. Thus promotion to full professor significantly diminishes the incentive to work long hours. Although the lack of family background information in our survey data prohibits us from making a definitive argument, the increase of family commitment, such as that arising from parenthood, arguably explains the decrease of total working hours as well.

The decrease of research hours over researchers' careers makes a stark contrast to the constancy of hours devoted to education and the slight increase of hours devoted to administrative tasks. This contrast could also well be explained by incentive structures set by academic institutions in Japan. Typically, departments in Japan assign mandatory teaching loads and committee tasks in an egalitarian way, regardless of researchers' research outputs. If a researcher seeks a teaching load reduction or an exemption from administrative tasks, she basically needs to exercise an "exit" option to move up to a higher-quality institution that offers a better package of teaching load and administrative tasks, but exercising this "exit" option is sometimes costly because of family and other reasons. Thus, egalitarian task assignment rules explain the combination of the decrease in research time and the constancy of education and administration time. 
The reallocation of time from research to administrative tasks is also a natural consequence of a promotion from being one of many players to leading a team at various levels. The decrease in time devoted to academic research explains a substantial part of senior researchers' decline in research output. These findings from Japanese academics reconfirm findings from other countries about the career transitions of researchers measured by the order of authorship or time use (see Gingras et al. (2008) and Costas and Bordons (2011) for the authorship order; Link et al. (2008) and Bentley and Kyvik (2013) for time use).

Our findings imply that a decrease in physical and mental abilities is not the sole explanation for senior researchers' decline in research output. Therefore, there is room to improve senior researchers' output by offering a better incentive scheme to induce them to expend more effort on research. In designing research incentives for senior researchers, we should pay careful attention to the fact that the power incentive in a multi-task environment generally distorts the effort allocation across tasks. The power incentive given to the research output of senior researchers, however, would not crowd out such activities as research fundraising and mentoring junior researchers, because these activities are complementary to research activity, as funding agencies tend to fund large-scale projects based on the PI's research achievement and large-scale projects tend to involve a large number of researchers involving mentoring junior researchers. The power incentive, in contrast, may crowd out educational activities, because education, particularly undergraduate education, is not necessarily complementary with research activities; one could be a very effective undergraduate instructor without being a good researcher (Hattie and Marsh, 1996). Thus proper incentives should be given to educational activities to counter a possible crowding out caused by the research incentive given to senior researchers. An incentive design that induces specialization in either research or education among senior academics would be a viable option. 


\section{References}

Bradford, B., Foltz, J., \& Prager, D. (2014). Making time for science. Research Policy, 43, 21-31.

Bentley, P., \& Kyvik, S. (2013). Individual differences in faculty research time allocations across 13 countries. Research in Higher Education, 54(3), 329-348.

Costas, R., \& Bordons, M. (2011). Do age and professional rank influence the order of authorship in scientific publications? Some evidence from a micro-level perspective. Scientometrics, 88(1), 145161

Costas, R., van Leeuwen, T. N., \& Bordons, M. (2010). A bibliometric classificatory approach for the study and assessment of research performance at the individual level: The effects of age on productivity and impact. Journal of American Society of Information Science and Technlogy, 61(8), 1564-1581.

Diamond, A. M. (1986). The life-cycle research productivity of mathematicians and scientists. Journal of Gerontology, 41(4), 520-525.

European Commission. (2009). Feasibility Study for Creating a European University Data Collection. http://ec.europa.eu/research/era/docs/en/eumida-final-report.pdf

Gingras, Y., Larivière, V., Macaluso, B., \& Robitaille, J.-P. (2008). The effects of aging on researchers' publication and citation patterns. PLOS ONE, 3(12), e4048.

Hattie, J., \& Marsh, H. W. (1996). The relationship between research and teaching: A meta-analysis. Review of Educational Research. 66(4), 507-542.

Kanda, Y., \& Tomizawa, H. (2015). Changes in the ratio of time spent on work activities by university \& college faculty members - A comparison of results of the "Survey of full-time equivalency data at universities and colleges" of 2002, 2008 and 2013. NISTEP Research Material 236 (in Japanese). http://data.nistep.go.jp/dspace/handle/11035/3027

Kyvik, S., \& Olsen, T. (2008). Does the aging of tenured academic staff affect the research performance of universities? Scientometrics, 76(3), 439-455. 
Levin, S., \& Stephan, P. (1991). Research productivity over the life cycle: Evidence for academic scientists. American Economic Review, 81(1), 114-132.

Link, A., Swann, C., \& Bozeman, B. (2008). A time allocation study of university faculty. Economics of Education Review, 27(4), 363-374.

Ministry of Education, Culture, Sports, Science and Technology. (2009). Survey on full-time equivalents at universities.

http://www.mext.go.jp/b_menu/houdou/21/09/1283868.htm

Organisation for Economic Co-operation and Development. (2002). Frascati manual: Proposed standard practice for surveys on research and experimental development, 6th edition. http://www.oecd.org/sti/frascatimanual

Oster, S., \& Hamermesh, D. (1998). Aging and productivity among economists. Review of Economics and Statistics, 80(1), 154-156.

Stroebe, W. (2010). The graying of academia: Will it reduce scientific productivity? American Psychologist, 65(7), 660-673.

Taylor, W., Fender, B., \& Burke, K. (2006). Unraveling the academic productivity of economists: The opportunity costs of teaching and service. Southern Economic Journal, 72(4), 846-859. 
Table 1 Descriptive statistics of the analysis sample, 2008, researchers in all fields

\begin{tabular}{|c|c|c|c|}
\hline Variable & Mean & $\begin{array}{l}\text { Standard } \\
\text { deviation }\end{array}$ & $\%$ of zero \\
\hline \multicolumn{4}{|l|}{ Time use (from April 2007 to March 2008) } \\
\hline Annual total hours & 2927 & 1073 & $2.1 \%$ \\
\hline Annual research hours & 1159 & 793 & $2.9 \%$ \\
\hline Annual education hours & 765 & 499 & $3.3 \%$ \\
\hline Annual administrative and other hours & 552 & 432 & $7.4 \%$ \\
\hline Annual education related service hours & 138 & 213 & $46.9 \%$ \\
\hline Annual research related service hours & 177 & 264 & $43.6 \%$ \\
\hline Annual service hours, not related to education or research & 136 & 456 & $81.2 \%$ \\
\hline \multicolumn{4}{|l|}{ Output measures (November 1, 2005 - October 31, 2008) } \\
\hline First-authored refereed publications in foreign language & 1.6 & 2.7 & $49.0 \%$ \\
\hline Refereed publications in foreign language & 7.0 & 9.6 & $25.5 \%$ \\
\hline Publications in Japanese language & 5.6 & 9.7 & $21.1 \%$ \\
\hline \multicolumn{4}{|l|}{ Academic field of own major (\%) } \\
\hline Humanities & $6.24 \%$ & & \\
\hline Law and political science & $2.65 \%$ & & \\
\hline Economics and business & $4.21 \%$ & & \\
\hline Other social sciences & $3.22 \%$ & & \\
\hline Science - theoretical & $6.20 \%$ & & \\
\hline Science- experimental & $15.23 \%$ & & \\
\hline Engineering & $18.26 \%$ & & \\
\hline Agricultural science & $14.10 \%$ & & \\
\hline Agricultural engineering & $2.41 \%$ & & \\
\hline Agricultural economics & $0.90 \%$ & & \\
\hline Basic medicine & $7.47 \%$ & & \\
\hline Clinical medicine & $5.91 \%$ & & \\
\hline Basic dentistry & $0.90 \%$ & & \\
\hline Clinical dentistry & $1.37 \%$ & & \\
\hline Pharmaceutical sciences & $2.84 \%$ & & \\
\hline Other health sciences & $2.79 \%$ & & \\
\hline Home economics & $0.61 \%$ & & \\
\hline Education & $2.65 \%$ & & \\
\hline Art & $0.61 \%$ & & \\
\hline Other & $1.42 \%$ & & \\
\hline
\end{tabular}


Rank

Professor

$40.5 \%$

Associate professor

$34.7 \%$

Assistant professor (kousi)

$10.5 \%$

Lecturer (jokyo)

$14.3 \%$

Age

45.6

National and public universities

$55.4 \%$

Research institute

$4.2 \%$

Fixed term contract

$19.0 \%$

Adjunct affiliation in other department

$15.5 \%$

Adjunct affiliation in other university

$17.4 \%$

Adjunct affiliation other than universities

$16.9 \%$

Foreign nationality

$1.2 \%$

Female

$11.1 \%$

Number of institutions for which the respondent has ever

3.0

worked

$84.9 \%$ 
Table 2 Aging and academic publications, number of publications in the last three years

\begin{tabular}{|c|c|c|c|c|c|c|}
\hline & (1) & (2) & (3) & (4) & (5) & (6) \\
\hline Dep. Var. & \multicolumn{2}{|c|}{$\begin{array}{c}\text { First authorship in foreign-language, } \\
\text { refereed journals }\end{array}$} & \multicolumn{2}{|c|}{$\begin{array}{l}\text { All articles in foreign-language refereed } \\
\text { journals }\end{array}$} & \multicolumn{2}{|c|}{$\begin{array}{c}\text { Japanese articles, including non-refereed } \\
\text { articles }\end{array}$} \\
\hline \multirow[t]{2}{*}{$35-39$} & -0.472 & $-0.723 * *$ & 1.044 & -0.259 & $1.480^{*}$ & 0.738 \\
\hline & $(0.300)$ & $(0.317)$ & $(0.789)$ & (0.828) & $(0.866)$ & $(0.903)$ \\
\hline \multirow[t]{2}{*}{$40-44$} & -0.493 & $-0.910 * *$ & $2.293 *$ & 0.203 & 1.245 & -0.109 \\
\hline & $(0.344)$ & $(0.360)$ & (1.231) & (1.310) & (1.048) & (1.085) \\
\hline \multirow[t]{2}{*}{$45-49$} & $-0.866 * *$ & $-1.338 * * *$ & $2.783^{*}$ & -0.252 & 1.933 & 0.085 \\
\hline & $(0.421)$ & $(0.435)$ & (1.551) & (1.596) & (1.210) & (1.206) \\
\hline \multirow[t]{2}{*}{$50-54$} & $-0.828 * *$ & $-1.298 * * *$ & $3.529 * *$ & 0.061 & 1.693 & -0.401 \\
\hline & $(0.413)$ & $(0.433)$ & $(1.466)$ & (1.511) & (1.371) & (1.364) \\
\hline $55-60$ & $-0.916^{*}$ & $-1.335 * * *$ & $3.490 *$ & -0.445 & 0.136 & -2.207 \\
\hline Rank & & $X$ & & $\mathrm{X}$ & & $X$ \\
\hline Obs. & 2,114 & 2,093 & 2,114 & 2,093 & 2,114 & 2,093 \\
\hline $\mathrm{R}^{2}$ & 0.113 & 0.126 & 0.206 & 0.24 & 0.132 & 0.154 \\
\hline
\end{tabular}

Note: Standard errors are in parentheses. All regression models include dummy variables for 12 category dummy variables for the major field of the department and 20 dummy variables for the field of the respondent's own study, the number of institutions for which the respondent has ever worked, whether the respondent has a doctoral degree, female dummy and foreign nationality dummy, the log of the number of university researchers and the size of Ph.D. students of the same cohort and field, and the log population of the same birth-year cohort. Columns (2), (4), and (6) also include dummies for job rank category (reference: professor), indicators for fixed-term contract, having adjunct affiliations to other institutes, and whether the individual researcher's field of study is the same as the major field of the department. 
Table 3 Aging and time use, annual hours

\begin{tabular}{|c|c|c|c|c|c|c|}
\hline & (1) & (2) & (3) & (4) & (5) & (6) \\
\hline Dep. Var. & \multicolumn{2}{|c|}{ Research } & \multicolumn{2}{|c|}{ Education } & \multicolumn{2}{|c|}{ Administration and other } \\
\hline \multirow[t]{2}{*}{$35-39$} & $-414.419 * * *$ & $-303.457 * * *$ & $163.608 * * *$ & $99.638 *$ & $118.768 * *$ & 78.599 \\
\hline & $(93.362)$ & (93.709) & $(52.257)$ & $(54.525)$ & (47.189) & $(48.857)$ \\
\hline \multirow[t]{2}{*}{$40-44$} & $-519.272 * * *$ & $-344.494 * * *$ & $198.321^{* * *}$ & 93.24 & $174.689 * * *$ & 103.538 \\
\hline & (114.286) & (115.984) & (69.117) & $(72.081)$ & $(60.766)$ & $(64.732)$ \\
\hline \multirow[t]{2}{*}{$45-49$} & $-696.595 * * *$ & $-512.210 * * *$ & $181.884^{* *}$ & 60.554 & $240.901^{* * *}$ & 128.15 \\
\hline & (132.268) & (134.384) & (84.398) & $(86.882)$ & $(75.740)$ & (79.159) \\
\hline \multirow[t]{2}{*}{$50-54$} & $-673.492 * * *$ & $-492.582 * * *$ & $145.615^{*}$ & 21.676 & $229.098 * * *$ & 96.346 \\
\hline & (133.075) & (137.353) & $(86.001)$ & $(89.622)$ & $(77.494)$ & $(80.944)$ \\
\hline \multirow[t]{2}{*}{$55-60$} & $-589.638 * * *$ & $-424.076 * * *$ & $266.673^{* *}$ & 165.519 & 113.396 & -32.287 \\
\hline & (144.859) & (149.488) & $(103.637)$ & (109.359) & (83.059) & (87.136) \\
\hline Obs. & 2,114 & 2,093 & 2,114 & 2,093 & 2,114 & 2,093 \\
\hline $\mathrm{R}^{2}$ & 0.18 & 0.193 & 0.147 & 0.16 & 0.057 & 0.073 \\
\hline
\end{tabular}

Note: Standard errors are in parentheses. All regression models include dummy variables for 12 category dummy variables for the major field of the department and 20 dummy variables for the field of the respondent's own study, the number of institutions for which the respondent has ever worked, whether the respondent has a doctoral degree, female dummy and foreign nationality dummy, the log of the number of university researchers and the size of Ph.D. students of the same cohort and field, and the log population of the same birth-year cohort. Columns (2), (4), and (6) also include dummies for job rank category (reference: professor), indicators for fixed-term contract, having adjunct affiliations to other institutes, and whether the individual researcher's field of study is the same as the major field of the department. 
Table 4a. Aging and the distribution of time use (without control for job ranks), annual hours

\begin{tabular}{lcccccccccc}
\hline & $\mathbf{( 1 )}$ & $\mathbf{( 2 )}$ & $\mathbf{( 3 )}$ & $\mathbf{( 4 )}$ & $\mathbf{( 5 )}$ & $\mathbf{( 6 )}$ & $\mathbf{( 7 )}$ & $\mathbf{( 8 )}$ & $\mathbf{( 9 )}$ \\
\hline Dep. Var. & & Research & & & Education & & \multicolumn{2}{c}{ Administration and other } \\
Percentile & 25 & 50 & 75 & 25 & 50 & 75 & 25 & 50 & 75 \\
$35-39$ & $-182.443^{* *}$ & $-316.801^{* * *}$ & $-532.763^{* * *}$ & $140.251^{* * *}$ & $135.008^{* *}$ & $162.834^{* *}$ & $94.122^{* * *}$ & $200.260^{* * *}$ & $190.395^{* *}$ \\
& $(82.925)$ & $(86.620)$ & $(170.884)$ & $(46.436)$ & $(66.374)$ & $(73.248)$ & $(27.378)$ & $(52.866)$ & $(74.477)$ \\
$40-44$ & -215.698 & $-443.457^{* * *}$ & $-842.016^{* * *}$ & $201.221^{* * *}$ & $199.040^{* *}$ & $199.882^{* *}$ & $179.585^{* * *}$ & $271.675^{* * *}$ & $222.576^{* *}$ \\
& $(152.758)$ & $(139.696)$ & $(227.404)$ & $(76.109)$ & $(89.121)$ & $(83.474)$ & $(38.671)$ & $(68.518)$ & $(101.095)$ \\
$45-49$ & -267.689 & $-565.321^{* * *}$ & $-1,022.624^{* * *}$ & $174.175^{* *}$ & $201.257^{*}$ & $179.873^{*}$ & $222.386^{* * *}$ & $292.268^{* * *}$ & $346.665^{* *}$ \\
& $(168.666)$ & $(172.929)$ & $(270.434)$ & $(71.376)$ & $(107.794)$ & $(93.308)$ & $(51.891)$ & $(79.739)$ & $(140.532)$ \\
$50-54$ & -210.865 & $-549.940^{* * *}$ & $-1,051.012^{* * *}$ & 112.535 & 156.996 & 128.15 & $225.738^{* * *}$ & $295.675^{* * *}$ & $304.556^{* *}$ \\
& $(164.543)$ & $(163.984)$ & $(244.405)$ & $(79.847)$ & $(110.400)$ & $(78.959)$ & $(45.474)$ & $(73.733)$ & $(130.480)$ \\
$55-60$ & -194.504 & $-435.403^{* * *}$ & $-925.022^{* * *}$ & $293.117^{* *}$ & $241.462^{* *}$ & $260.288^{*}$ & $151.468^{* *}$ & 166.129 & 145.778 \\
& $(152.154)$ & $(129.921)$ & $(269.880)$ & $(122.073)$ & $(116.897)$ & $(132.984)$ & $(69.479)$ & $(115.281)$ & $(179.168)$ \\
Obs. & 2,114 & 2,114 & 2,114 & 2,114 & 2,114 & 2,114 & 2,114 & 2,114 & 2,114 \\
Pseudo R ${ }^{2}$ & 0.094 & 0.110 & 0.128 & 0.121 & 0.100 & 0.087 & 0.043 & 0.051 & 0.046 \\
\hline
\end{tabular}

Note: Standard errors are in parentheses. All regression models include dummy variables for 12 category dummy variables for the major field of the department and 20 dummy variables for the field of the respondent's own study, the number of institutions for which the respondent has ever worked, whether the respondent has a doctoral degree, female dummy and foreign nationality dummy, the log of the number of university researchers and the size of Ph.D. students of the same cohort and field, and the log population of the same birth-year cohort. 
Table 4b. Aging and the distribution of time use (with control for job ranks), annual hours

\begin{tabular}{|c|c|c|c|c|c|c|c|c|c|}
\hline & (1) & (2) & (3) & (4) & (5) & (6) & (7) & (8) & (9) \\
\hline Dep. Var. & \multicolumn{3}{|c|}{ Research } & \multicolumn{3}{|c|}{ Education } & \multicolumn{3}{|c|}{ Administration and other } \\
\hline Percentile & 25 & 50 & 75 & 25 & 50 & 75 & 25 & 50 & 75 \\
\hline \multirow[t]{2}{*}{$35-39$} & $-140.793 *$ & $-169.786^{* *}$ & $-300.192 * *$ & $93.372 * *$ & 71.801 & 124.74 & 36.2 & $120.856 * * *$ & $120.954 * *$ \\
\hline & $(75.008)$ & (72.086) & $(148.041)$ & $(42.620)$ & $(70.645)$ & $(113.961)$ & $(35.990)$ & $(40.258)$ & (48.369) \\
\hline \multirow[t]{2}{*}{$40-44$} & -144.636 & $-210.267 * *$ & $-381.971 * *$ & $134.201 *$ & 77.116 & 108.503 & 71.477 & $140.775 *$ & 127.816 \\
\hline & $(112.505)$ & $(85.016)$ & $(192.616)$ & $(74.558)$ & $(76.326)$ & $(122.023)$ & $(56.305)$ & $(77.720)$ & $(107.598)$ \\
\hline \multirow[t]{2}{*}{$45-49$} & -182.847 & $-326.880 * * *$ & $-626.783 * * *$ & 120.181 & 101.808 & 80.388 & 90.275 & 137.967 & 200.019 \\
\hline & (140.536) & (96.402) & (224.251) & (82.827) & $(102.407)$ & (143.347) & (76.298) & (111.562) & (137.988) \\
\hline \multirow[t]{2}{*}{$50-54$} & -139.201 & $-310.872 * *$ & $-647.137 * * *$ & 55.842 & 32.264 & -2.862 & 83.325 & 104.684 & 106.975 \\
\hline & (147.257) & (131.992) & (226.147) & (95.081) & (103.330) & (139.467) & (79.592) & (109.314) & (142.096) \\
\hline $55-60$ & -169.405 & -233.676 & $-437.866^{*}$ & $174.793 *$ & 78.639 & 139.156 & 21.165 & 0.833 & -70.064 \\
\hline Obs. & 2,093 & 2,093 & 2,093 & 2,093 & 2,093 & 2,093 & 2,093 & 2,093 & 2,093 \\
\hline Pseudo $\mathrm{R}^{2}$ & 0.099 & 0.119 & 0.146 & 0.132 & 0.113 & 0.098 & 0.053 & 0.067 & 0.058 \\
\hline
\end{tabular}

Note: Standard errors are in parentheses. All regression models include dummy for job ranks, dummy variables for 12 category dummy variables for the major field of the department and 20 dummy variables for the field of the respondent's own study, the number of institutions for which the respondent has ever worked, whether the respondent has a doctoral degree, female dummy and foreign nationality dummy, the log of the number of university researchers and the size of Ph.D. students of the same cohort and field, the log population of the same birth-year cohort, dummies for job rank category (reference: professor), indicators for fixed-term contract, having adjunct affiliations to other institutes, and whether the individual researcher's field of study is the same as the major field of the department. 
Figure 1 Publication portfolio over age, number of publications in the last three years

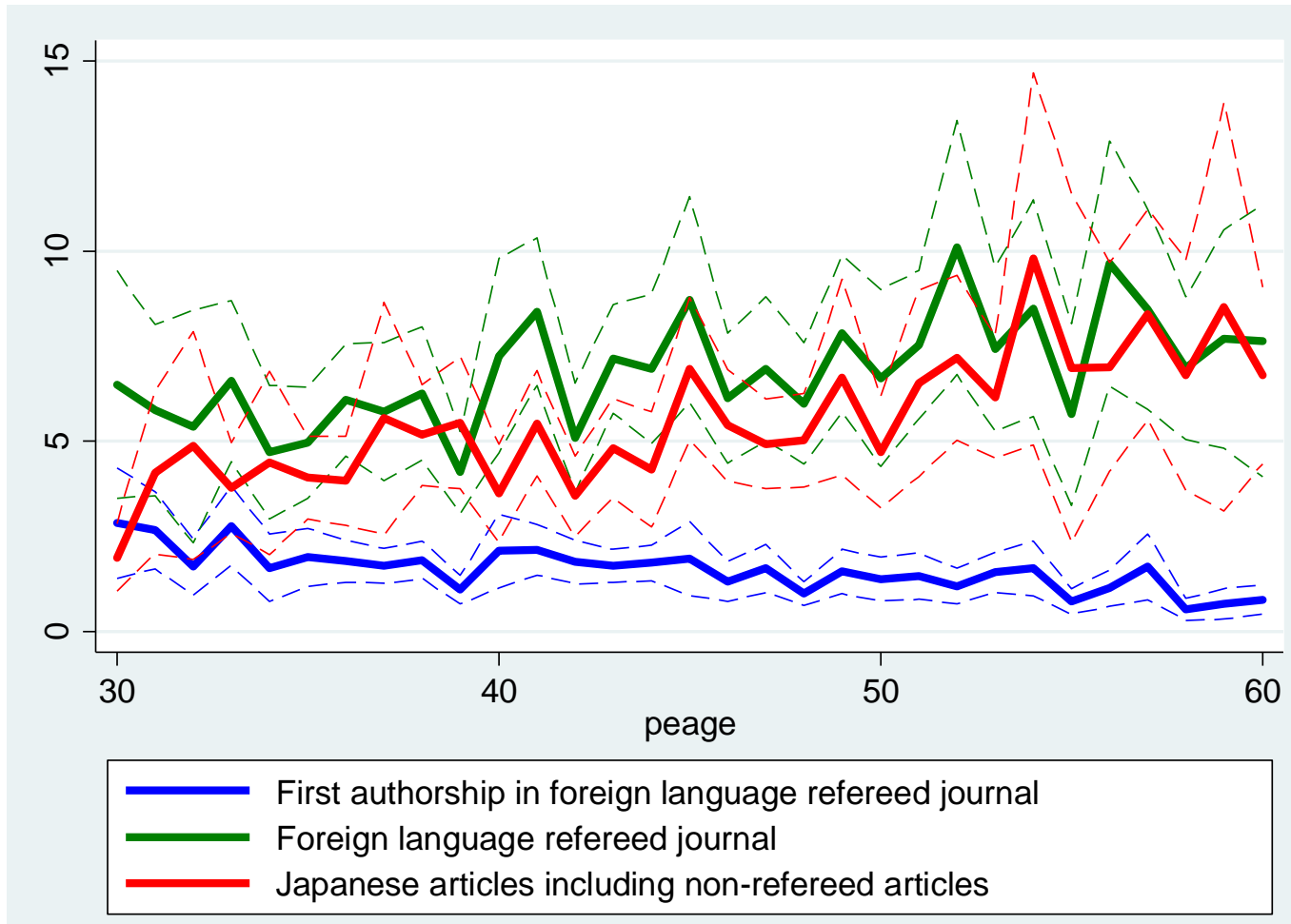

Note: Dashed lines are 95\% confidence intervals. 
Figure 2 Time use of researchers over age, annual hours

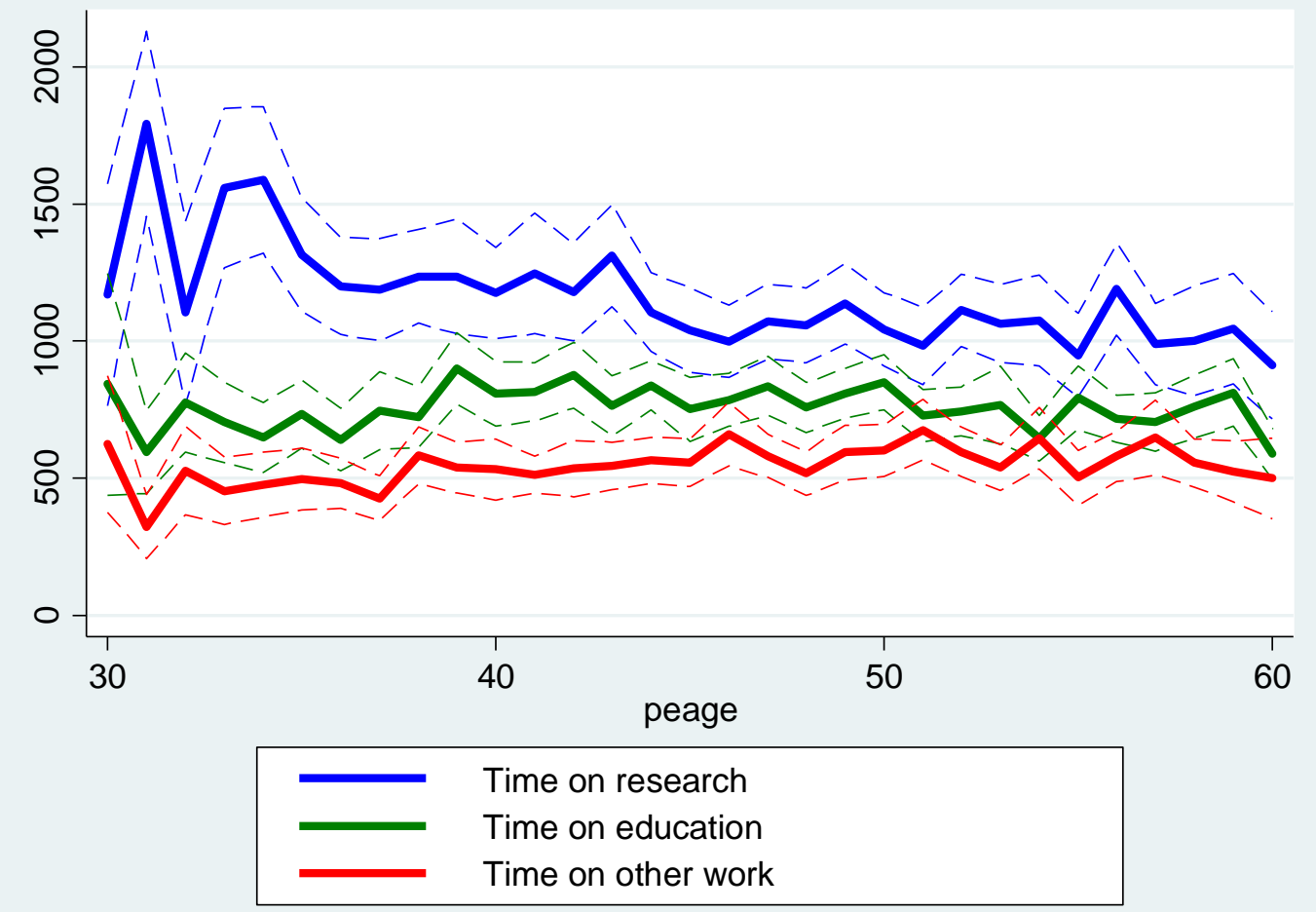

Note: Dashed lines are 95\% confidence intervals. 
Figure 3: Number of PIs receiving Grant-in-Aid for Specially Promoted Research (Tokubetsu Suisin) active as of December 2015 by age groups

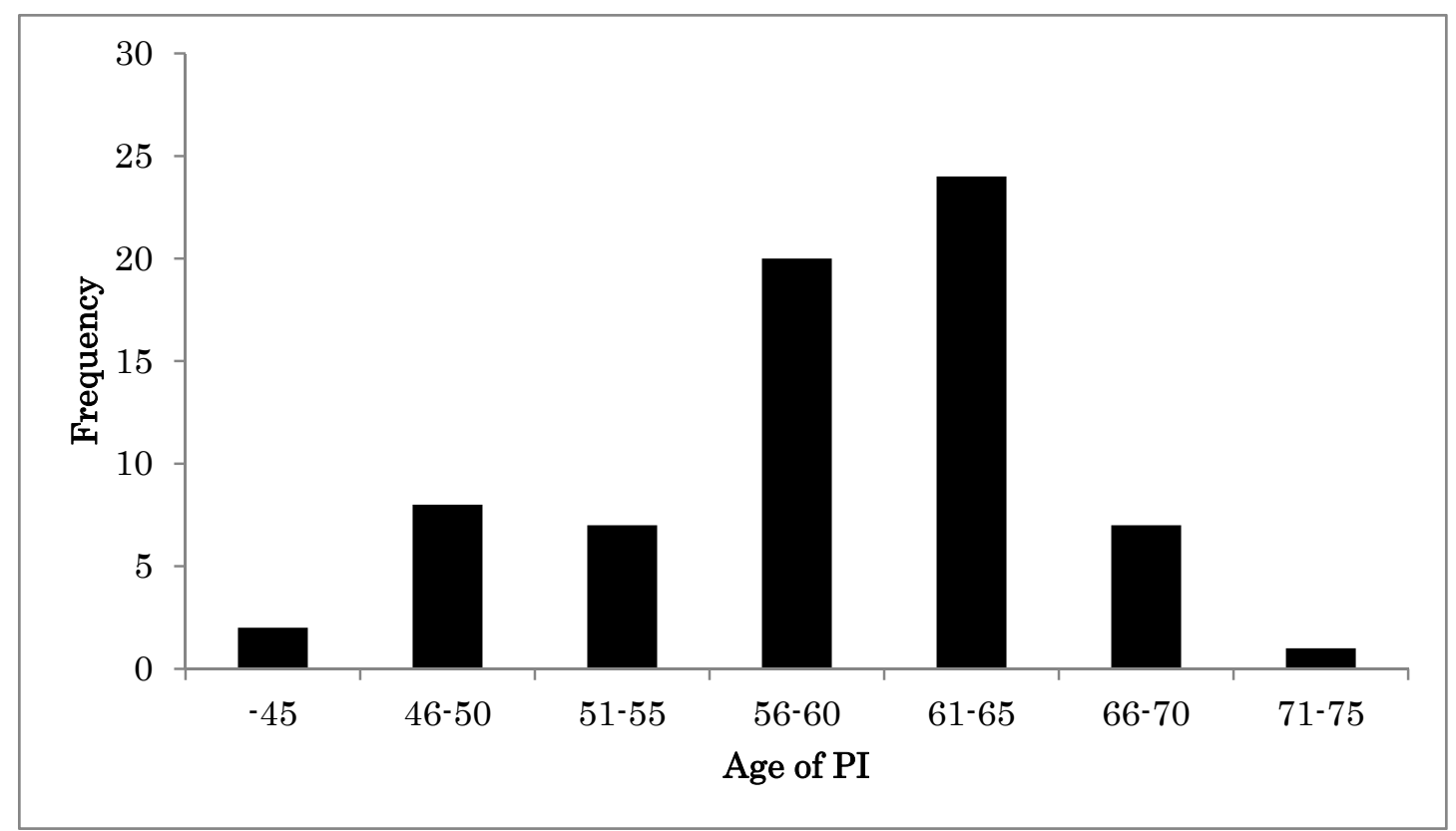

Note: Data are downloaded from the KAKEN database compiled by the National Institute of Information in December 2015. The number of observations with valid PI age is 69. The mean and median of PI age are 58.8 and 60.0, respectively. 
Figure 4: Age of PI and size of laboratory at Physics department of the University of Tokyo as of April 2016

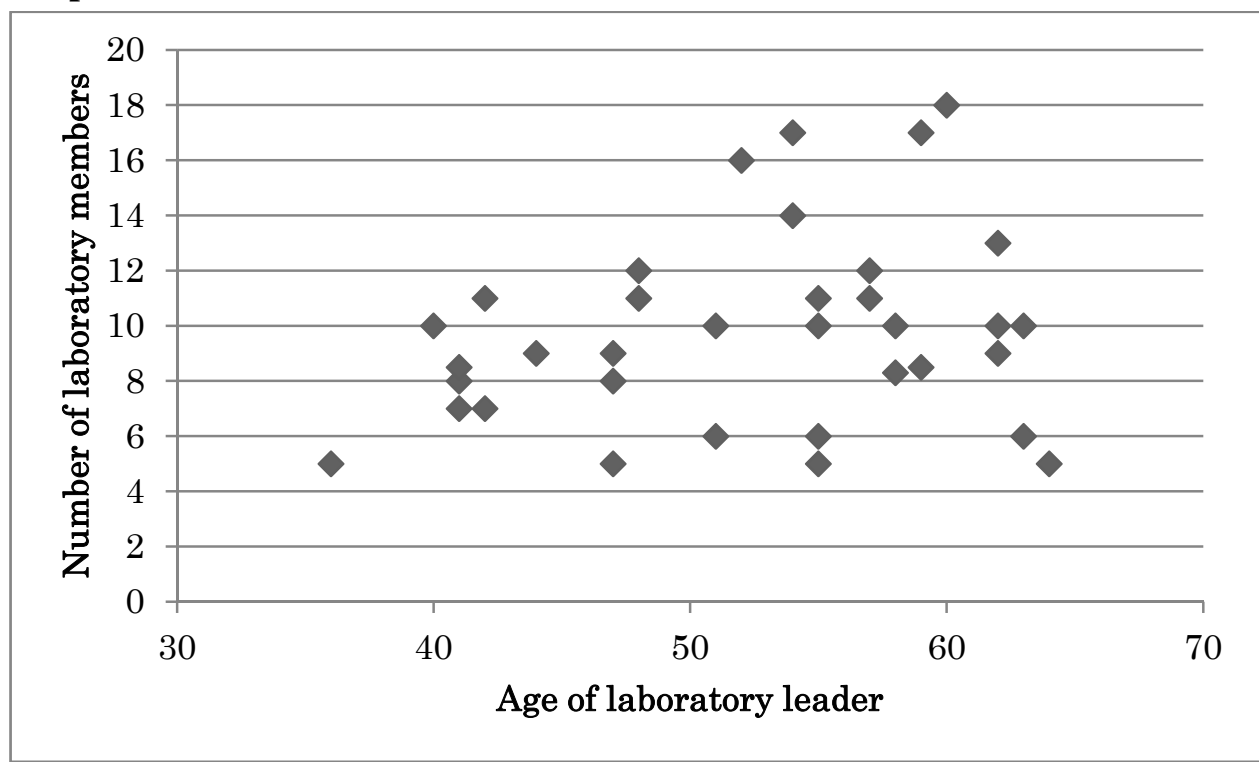

Note: Counts of laboratory members are based on each PI’s webpage. Some laboratories have more than one PI. In such cases, the number of laboratory members is prorated. 
Appendix table A1 Aging and academic publications with different cut-off values for the age groups

\begin{tabular}{|c|c|c|c|c|c|c|}
\hline & (1) & (2) & (3) & (4) & (5) & (6) \\
\hline Dep. Var. & \multicolumn{2}{|c|}{$\begin{array}{c}\text { First authorship in foreign-language, } \\
\text { refereed journals }\end{array}$} & \multicolumn{2}{|c|}{$\begin{array}{l}\text { All articles in foreign-language refereed } \\
\text { journals }\end{array}$} & \multicolumn{2}{|c|}{$\begin{array}{c}\text { Japanese articles, including non-refereed } \\
\text { articles }\end{array}$} \\
\hline \multirow[t]{2}{*}{ 33-37 } & -0.288 & -0.492 & 0.300 & -0.883 & 1.166 & 0.442 \\
\hline & $(0.344)$ & (0.337) & $(0.931)$ & $(0.956)$ & (1.030) & (1.036) \\
\hline \multirow[t]{2}{*}{$38-42$} & $-0.568 *$ & $-0.980 * * *$ & 1.312 & -0.893 & 1.166 & -0.412 \\
\hline & $(0.345)$ & (0.343) & (1.097) & (1.143) & (1.112) & (1.209) \\
\hline \multirow[t]{2}{*}{$43-47$} & $-0.832 *$ & $-1.300 * * *$ & 2.037 & -1.108 & 1.15 & -0.901 \\
\hline & $(0.425)$ & $(0.430)$ & (1.296) & (1.337) & $(1.250)$ & (1.325) \\
\hline \multirow[t]{2}{*}{$48-52$} & $-1.208 * * *$ & $-1.709 * * *$ & $2.456^{*}$ & -1.315 & 1.25 & -1.161 \\
\hline & $(0.446)$ & $(0.463)$ & (1.426) & (1.457) & (1.322) & $(1.400)$ \\
\hline $53-57$ & $-0.942 * *$ & $-1.464 * * *$ & $2.724^{*}$ & -1.413 & 1.672 & -0.881 \\
\hline \multirow[t]{2}{*}{$58-64$} & $-1.418 * * *$ & $-1.974 * * *$ & 1.954 & -2.466 & 0.734 & -1.884 \\
\hline & $(0.505)$ & $(0.525)$ & (1.860) & (1.881) & (1.773) & (1.846) \\
\hline Rank & & $X$ & & $\mathrm{X}$ & & $\mathrm{X}$ \\
\hline Obs. & 2,137 & 2,116 & 2,137 & 2,116 & 2,137 & 2,116 \\
\hline $\mathrm{R}^{2}$ & 0.113 & 0.126 & 0.207 & 0.241 & 0.132 & 0.154 \\
\hline
\end{tabular}

Note: Standard errors are in parentheses. All regression models include dummy variables for 12 category dummy variables for the major field of the department and 20 dummy variables for the field of the respondent's own study, the number of institutions for which the respondent has ever worked, whether the respondent has a doctoral degree, female dummy and foreign nationality dummy, the log of the number of university researchers and the size of Ph.D. students of the same cohort and field, and the log population of the same birth-year cohort. 
Appendix table A2 Aging and time use with different cut-off values for the age groups

\begin{tabular}{|c|c|c|c|c|c|c|}
\hline & (1) & (2) & (3) & (4) & (5) & (6) \\
\hline Dep. Var. & \multicolumn{2}{|c|}{ Research } & \multicolumn{2}{|c|}{ Education } & \multicolumn{2}{|c|}{ Administration and other } \\
\hline \multirow[t]{2}{*}{ 33-37 } & -124.189 & -21.134 & 52.738 & -3.522 & 85.639 & 59.595 \\
\hline & (116.297) & $(114.276)$ & $(64.192)$ & (63.080) & $(54.784)$ & $(55.374)$ \\
\hline \multirow[t]{2}{*}{$38-42$} & $-231.649 *$ & -31.159 & $193.710 * * *$ & 94.735 & $191.444^{* * *}$ & $136.395 * *$ \\
\hline & (125.086) & (124.529) & $(70.145)$ & $(70.834)$ & (61.898) & (63.888) \\
\hline \multirow[t]{2}{*}{$43-47$} & $-320.655 * *$ & -81.88 & $186.057 * *$ & 75.035 & $254.522 * * *$ & $167.043^{* *}$ \\
\hline & $(142.754)$ & $(143.890)$ & $(80.670)$ & (82.698) & (73.618) & (75.164) \\
\hline \multirow[t]{2}{*}{$48-52$} & $-358.878 * *$ & -123.937 & $170.123 *$ & 47.988 & $249.513 * * *$ & 129.573 \\
\hline & (153.310) & (156.375) & (89.267) & (91.594) & $(80.879)$ & $(82.423)$ \\
\hline \multirow[t]{2}{*}{$53-57$} & $-332.100 * *$ & -84.428 & 130.5 & 7.237 & $201.187 * *$ & 63.115 \\
\hline & (154.702) & (158.411) & (93.767) & (97.286) & (83.531) & (85.328) \\
\hline $58-64$ & (172.707) & (175.000) & (105.650) & (109.005) & (95.424) & (96.125) \\
\hline Rank & & $\mathrm{X}$ & & $X$ & & $\mathrm{X}$ \\
\hline Obs. & 2,137 & 2,116 & 2,137 & 2,116 & 2,137 & 2,116 \\
\hline $\mathrm{R}^{2}$ & 0.18 & 0.195 & 0.146 & 0.16 & 0.059 & 0.073 \\
\hline
\end{tabular}

Note: Standard errors are in parentheses. All regression models include dummy variables for 12 category dummy variables for the major field of the department and 20 dummy variables for the field of the respondent's own study, the number of institutions for which the respondent has ever worked, whether the respondent has a doctoral degree, female dummy and foreign nationality dummy, the log of the number of university researchers and the size of Ph.D. students of the same cohort and field, and the log population of the same birth-year cohort. 
Appendix table A3 Aging and academic publications: Tobit model

\begin{tabular}{|c|c|c|c|c|c|c|}
\hline & (1) & (2) & (3) & (4) & (5) & (6) \\
\hline Dep. Var. & \multicolumn{2}{|c|}{$\begin{array}{c}\text { First authorship in foreign-language, } \\
\text { refereed journals }\end{array}$} & \multicolumn{2}{|c|}{$\begin{array}{l}\text { All articles in foreign-language refereed } \\
\text { journals }\end{array}$} & \multicolumn{2}{|c|}{$\begin{array}{l}\text { Japanese articles, including non-refereed } \\
\text { articles }\end{array}$} \\
\hline \multirow[t]{2}{*}{$35-39$} & -0.531 & $-0.841^{*}$ & 1.061 & -0.386 & $3.038 * * *$ & 1.764 \\
\hline & $(0.462)$ & $(0.486)$ & (1.048) & $(1.094)$ & (1.151) & (1.177) \\
\hline $40-44$ & -0.738 & $-1.273^{* *}$ & 2.142 & -0.212 & $2.440^{*}$ & 0.34 \\
\hline \multirow[t]{2}{*}{$45-49$} & $-1.510 * *$ & $-2.117 * * *$ & 2.507 & -1.106 & $3.176^{*}$ & 0.342 \\
\hline & $(0.742)$ & $(0.768)$ & $(2.042)$ & (2.107) & (1.624) & (1.615) \\
\hline \multirow[t]{2}{*}{$50-54$} & $-1.486^{* *}$ & $-2.084^{* * *}$ & 3.09 & -1.174 & $3.178 *$ & -0.038 \\
\hline & $(0.742)$ & $(0.780)$ & (1.960) & $(2.023)$ & (1.759) & $(1.740)$ \\
\hline $55-59$ & $-2.185^{* * *}$ & $-2.716^{* * *}$ & 2.059 & -2.805 & 1.832 & -1.562 \\
\hline \multirow[t]{2}{*}{$60-64$} & $-1.987 *$ & $-2.664 * *$ & 1.061 & -0.386 & $3.038 * * *$ & 1.764 \\
\hline & (1.039) & (1.075) & (1.048) & $(1.094)$ & (1.151) & (1.177) \\
\hline Rank & & $X$ & & $\mathrm{X}$ & & $X$ \\
\hline Obs. & 2,137 & 2,116 & 2,137 & 2,116 & 2,137 & 2,116 \\
\hline
\end{tabular}

Note: Standard errors are in parentheses. This is a tobit version of Table 2; the same notes apply to this table. 